\title{
Protocol Risk Assessment
}

National Cancer Institute

\section{Source}

National Cancer Institute. Protocol Risk Assessment. NCI Thesaurus. Code C139277.

The potential future harm that may arise from some protocol-related activity. 